\title{
Narcolepsy Secondary to Fourth Ventricular Subependymoma
}

\author{
T.K.F. Ma, L.C. Ang, M. Mamelak, S.J. Kish, B. Young and A.J. Lewis
}

\begin{abstract}
Background: Secondary (symptomatic) narcolepsy is rare. We report a subependymoma of the fourth ventricle associated with narcolepsy. The patient was a 50-year-old woman with a long history of narcolepsy who died of colonic carcinoma with no cerebral metastasis. She was positive for HLA-DR2. At autopsy there was a tumour dorsal to the fourth ventricle which involved the midbrain tectum and rostral pons. Histologic examination of the tumour confirmed it to be a subependymoma. Methods: Review of the previous cases of secondary narcolepsy was made with particular reference to the anatomical location of the lesions. Results: Most of the lesions were found around the third ventricle and rostral brainstem. Conclusions: Knowing the anatomical localization of the pathological changes in secondary narcolepsy could be important in improving our understanding of its pathogenesis.
\end{abstract}

RÉSUMÉ: Narcolepsie associée à un subépendymome du quatrième ventricule: à propos d'un cas - revue de la littérature sur la narcolepsie secondaire. Introduction: La narcolepsie secondaire (symptomatique) est rare. Nous rapportons un subépendymome du quatrième ventricule associé à la narcolepsie. Il s'agit d'une femme de 50 ans qui avait une longue histoire de narcolepsie et qui est décédée d'un cancer du côlon, sans métastase cérébrale. Elle était porteuse du HLA-DR2. À l'autopsie, il y avait une tumeur à la région postérieure du quatrième ventricule qui impliquait le toit du mésencéphale et la région rostrale du pont. L'examen histologique de la tumeur a confirmé qu'il s'agissait d'un subépendymome. Méthodes: Nous avons effectué une revue de la littérature concernant les cas de narcolepsie secondaire en portant une attention particulière au site anatomique des lésions. Résultats: La plupart des lésions étaient situées autour du troisième ventricule et de la partie rostrale du tronc cérébral. Conclusions: Le fait de connaitre le site anatomique des changements pathologiques dans la narcolepsie secondaire pourrait être important pour améliorer notre compréhension de la pathogenèse de la narcolepsie.

Can. J. Neurol. Sci. 1996; 23: 59-62

Narcolepsy is a chronic neurological disorder characterized by excessive daytime sleepiness, cataplexy, premature onset of rapid eye movement (REM) sleep and impaired sleep-wake regulation. Sleep paralysis and hypnagogic hallucinations are also commonly associated symptoms. It can be primary or secondary (symptomatic). The majority of the patients are of the primary type without any identifiable brain lesion. The onset of symptoms is usually in the second or third decade of life. There is a strong genetic predisposition and the majority of patients are HLA-DR2 and HLA-DQw 1 positive. Secondary (symptomatic) narcolepsy, in which an identifiable brain lesion is found, is rare. They have been reported in patients with third ventricle glioma, ${ }^{1}$ midbrain glioblastoma multiforme, ${ }^{2}$ cerebral sarcoidosis, ${ }^{3-5}$ colloid cyst, ${ }^{3}$ pituitary adenoma, ${ }^{3}$ pontine infarcts, ${ }^{6.7}$ hypothalamic syndrome, ${ }^{5.8}$ craniopharyngioma, ${ }^{5.9 .10}$ and malignant $1 y m-$ phoma. ${ }^{11}$ We herein report the first case of a subependymoma associated with narcolepsy.

\section{Case Report}

A 50-year-old woman had a history of excessive drowsiness in the daytime associated with cataplexy since her teenage years. Investigations in the sleep laboratory revealed short REM sleep latency at night, four sleep latencies of less than 5 minutes during four 20minute nap opportunities in the day and the presence of REM sleep in two of these four naps. A diagnosis of narcolepsy was confirmed. She had been treated with low doses of D-amphetamine for many years and followed up in a sleep disorder clinic (M.M.). She died of colonic carcinoma with no cerebral metastasis. She had been receiving morphine and chemotherapeutic agents for her carcinoma but did not take Damphetamine for six months prior to death. She was determined to be HLA-DR2 positive after her death by immune typing of her surviving husband and their children. An autopsy restricted to the brain was subsequently performed.

\section{Autopsy findings}

At autopsy, there was a firm whitish-grey but vascular tumour in the midbrain tectum which extended the entire length of the superior medullary velum, resulting in lateral displacement and distortion of the colliculi. It measured $4.5 \mathrm{~cm}$ along the neuroaxis and $1 \mathrm{~cm} \times 1 \mathrm{~cm}$ in cross sectional area. It had a large intraventricular component and was attached to the dorsal upper fourth ventricle and aqueduct with slight adhesions to the fourth ventricular floor (Figure 1). The transverse sections showed that it involved the tegmentum of the rostral pons. Examination of the brain revealed marked hydrocephalus (caudate-callosal distance up to $0.8 \mathrm{~cm}$ ) with fenestration of the septum pellucidum

From the Division of Pathology (T.K.F.M., L.C.A., A.J.L., B.Y.), Sunnybrook Health Science Centre, Department of Psychiatry (M.M.). Baycrest Centre, and Clarkc Institute of Psychiatry (S.J.K.), University of Toronto. Toronto. RECEIVED MAY 31, 1995. ACCEPTED IN FINAL FORM SPETEMBER 19.1995.

Reprint requests to: L.C. Ang, M.D., F.R.C.P.(C). Division of Pathology (Neuropathology) E419, Sunnybrook Health Science Centre, University of Toronto. 2075 Bayview Avenue, North York, Ontario. Canada M4N 3M5 
and mild widening of the third ventricle. No metastatic colonic carcinoma was found.

\section{Histologic examination}

The tumour is hypocellular with clustering of ependymal cells admixed with astrocytic cells in a fibrillary matrix background (Figure 2 ). The tumour cells possess uniform delicate nuclei with fine chromatin and inconspicuous nucleoli. Nuclear pleomorphism is absent and there are no mitotic figures or tumour necrosis. There is prominent vascularity without features of vascular tumour or malformation. No perivascular pseudorosettes or ependymal true rosettes are seen. Glial fibrillary acidic protein (GFAP) is localized in some of the tumour cells. The tumour cells infiltrate into the dorsal raphe nucleus and locus ceruleus. The neurons in the locus ceruleus are pyknotic with vacuolated cytoplasm and poorly pigmented. There is also some loss of neurons in the dorsal raphe nucleus. The overall features are those of a subependymoma of the fourth ventricle involving the tectum of the midbrain and dorsal rostral pons.

\section{Discussion}

Secondary (symptomatic) narcolepsy is rare. To our knowledge there are sixteen such cases reported in the English literature (Table 1). The pathological findings are comprised of tumours (astrocytoma, craniopharyngioma, pituitary adenoma, malignant lymphoma), sarcoidosis, colloid cyst and brain stem infarcts. The lesions are mainly localized in the periventricular (third ventricle), hypothalamic and brain stem regions. In only four cases, including the present one, the strategic location and size of the lesions have been associated with hydrocephalus., ${ }^{1,2,5}$ Therefore, it seems quite unlikely that hydrocephalus per se could be linked directly to the pathogenesis of narcolepsy. For the two cases with hypothalamic syndrome, ${ }^{5,8}$ there were actually no identifiable lesions in the hypothalamus and so strictly speaking should be excluded from this category. The present case of subependymoma of the fourth ventricle was previously included in a neurochemical study on the neurotransmitter changes in human narcolepsy but the relationship between the tumour and narcolepsy had not been discussed in the paper. ${ }^{12}$

Subependymoma is a highly differentiated, slow growing glioma which is composed of ependymal and astrocytes arising from the wall of the ventricular system. It is rare and contributes

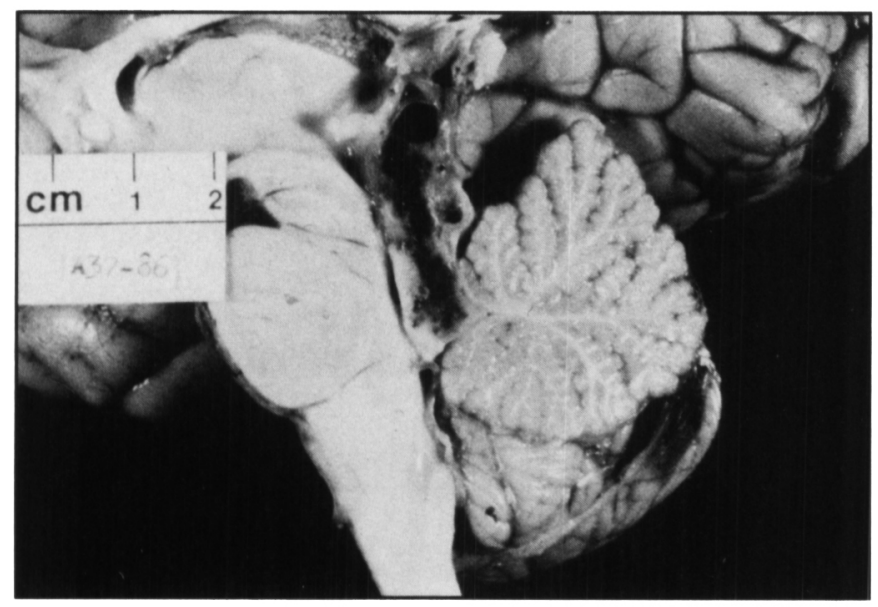

Figure 1: Sagittal section of the brain showing the tumour which involves the fourth ventricle, tectum of rostral pons and midbrain. Note the markedly dilated blood vessels with hemorrhages. to $0.7 \%$ of all intracranial neoplasm in some reported series. ${ }^{13}$ The majority (up to $70 \%$ ) are asymptomatic and found incidentally at autopsy in the fourth ventricle of middle-aged or elderly subjects. ${ }^{14}$ Other sites include the wall of lateral ventricle, septum pellucidum, foramen of Monro, aqueduct and rarely spinal cord.

In a minority of patients, subependymoma is symptomatic though this depends very much on its size and location. ${ }^{14}$ The mean age of all patients in 49 years and $80 \%$ are males. For asymptomatic patients, the mean age is 59 years and for symptomatic patients the mean age is 39 years. The mean size of the tumour is $0.8 \mathrm{~cm}$ in asymptomatic and $4.5 \mathrm{~cm}$ in symptomatic cases. The tumour may be single or multiple. It appears small, hard, lobulated and is usually sharply demarcated from the adjacent brain tissue and tends to grow intraventricularly. Cyst formation, calcification and hemorrhages are common.

In the present case, the tumour is extensive, involving the four ventricles, tectum and rostral pons. The differential diagnoses of low grade astrocytoma and ependymoma are considered. The histologic findings with clustering of tumour cells, and admixture of ependymal cells and astrocytes exclude the diagnosis of a low grade astrocytoma. The lack of cellularity, absence of perivascular pseudorosettes and true ependymal rosettes are against an ependymoma. A distinctive feature in this tumour is its prominent vascularity which can be identified grossly. The vessels, however, are thin walled and less compact, unlike those of a cavernous hemangioma. There are also no abnormal arteries or veins to suggest a diagnosis of arteriovenous malformation. The distinctive infiltrating nature of this subependymoma correlates with the particular symptoms associated, i.e., narcolepsy, which is not reported in all the previous cases of symptomatic subependymoma.

Recent evidence shows that narcolepsy is associated with the premature onset of REM sleep. Abnormal activity of neural systems involved in REM sleep may contribute to the pathogenesis of narcolepsy. ${ }^{15}$ It has been shown in experimental animals that the essential elements for the generation of REM sleep are located in the pons. The rostral pontine tegmentum and the adjacent area

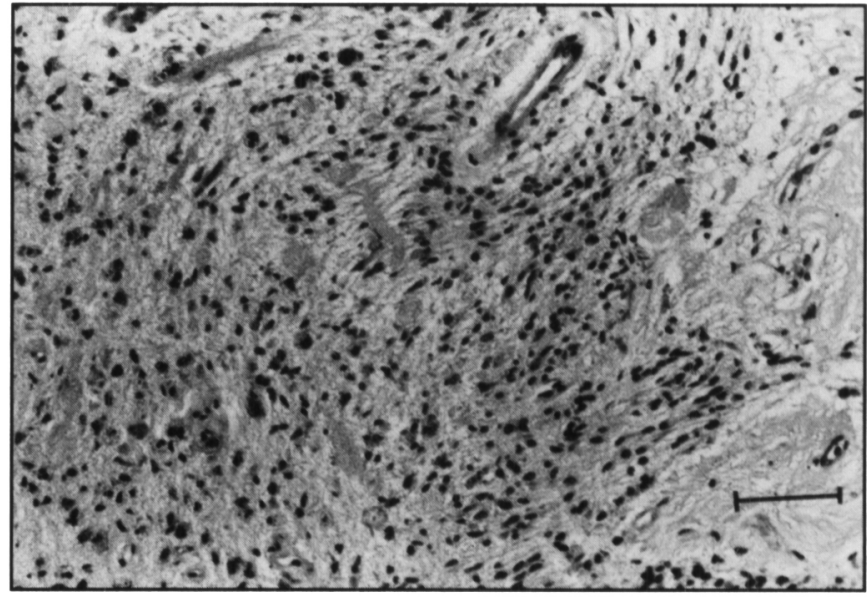

Figure 2: There is clustering of the tumour cells which possess oval nuclei with fine chromatin and inconspicuous nucleoli in a fibrillary background. (Hematoxylin-eosin; Bar $=64 \mu \mathrm{m}$ ) 
Table 1: A Summary of Reported Cases of Secondary Narcolepsy.

\begin{tabular}{|c|c|c|c|}
\hline AUTHOR & SITE OF LESION & PATHOLOGY & HLA TYPE \\
\hline Stahl et al. ${ }^{2}$ & midbrain, hypothalamus & glioblastoma multiforme & NA \\
\hline Pritchard et al. ${ }^{3}$ & pituitary & adenoma & $\mathrm{NA}$ \\
\hline Pritchard et al. ${ }^{3}$ & 3rd ventricle & colloid cyst & NA \\
\hline Pritchard et al. ${ }^{3}$ & not mentioned & sarcoidosis & NA \\
\hline Gurewitz et al. ${ }^{8}$ & hypothalamus & hypothalamic syndrome & $\mathrm{NA}$ \\
\hline Rubinstein et al. ${ }^{4}$ & hypothalamus & sarcoidosis & $\mathrm{NA}$ \\
\hline Aldrich et al. ${ }^{5}$ & surpasellar & craniopharyngioma & DR2+ \\
\hline Aldrich et al. ${ }^{5}$ & hypothalamus & hypothalamic syndrome & DR2+ \\
\hline Aldrich et al. ${ }^{3}$ & 3rd ventricle & sarcoidosis & DR2- \\
\hline
\end{tabular}

$\mathrm{NA}=$ not available

SAH = subarachnoid hemorrhage

as well as part of the locus ceruleus contain the so-called "REM on" cells which are selectively activated during REM sleep and are essential for its expression. Many of these REM-on neurons are cholinergic and play a central role in the generation of REM sleep. Located around the same regions as pontine REM-on cells are the REM-off cells which are selectively silent during REM sleep. These include the serotoninergic neurons of the raphe nuclei and noradrenergic neurons of the locus ceruleus which appear to play a permissive role through modulation of activity of REM-on neurons. There are two areas in the medulla, the nucleus magnocellularis and nucleus paramedianus, which are involved in the expression of muscle atonia during REM sleep and atonia could also be induced by infusion of muscarinic agonists into the pontine tegmentum.

Involvement of the pontine tegmentum and locus ceruleus by the subependymoma prompt us to consider its role in our patient's narcoleptic symptoms rather than just dismissing it as an incidental finding. The low frequency of $4^{\text {th }}$ ventricular subependymoma and the extreme rarity of secondary narcolepsy also suggest that the occurrence of these two separate processes in one patient is not likely to be coincidental. The damage of these brain stem structures would disturb the REM sleep predisposing the patient to narcoleptic symptoms. We are unable to establish the temporal relationship between the onset of narcoleptic symptoms and occurrence of the tumour. As subependymoma is usually asymptomatic until it has acquired a certain size, it is impossible to confirm its presence unless an investigative procedure such as CT scan was performed at the very onset of narcolepsy symptoms many years ago. That this patient is HLA-DR2 positive does not automatically imply that the narcolepsy is primary. Three of the secondary narcoleptic patients we reviewed have been reported positive for HLADR2. ${ }^{5.10}$ It has been suggested that HLA-DR2 may be an important prerequisite for secondary (symptomatic) narcolepsy. ${ }^{16}$
It is obvious from the review that in secondary narcoleptic patients the lesions involve mainly two regions of the brain; the hypothalamic/periventricular (third) region and the dorsal midbrain/rostral pons. Isolated cataplexy associated with brain stem lesion have also been reported recently; one with toxoplasmosis in the midbrain of a HIV positive patient, and the other patient with multiple sclerosis and pilocytic astrocytoma involving the ponto-medullary regions. ${ }^{17,18}$ It has been shown in animal studies that the peri-ventricular (third) and hypothalamic regions are involved in the regulation of REM sleep and sleep-wake cycles. ${ }^{15}$ Disturbance of areas responsible for either the generation (rostral pons) or timing (hypothalamus/periventricular) of REM sleep could be involved in pathogenesis of narcolepsy, though much has yet to be learned of the actual mechanism.

\section{ACKNOWLEDGement}

We thank Lina Paolucci and Norma Blythe for their assistance in the preparation of the manuscript.

\section{REFERENCES}

1. Anderson M, Salmon MV. Symptomatic cataplexy. J Neurol Neurosurg Psychiatry 1977; 40: 186-191.

2. Stahl SM, Layzer RB, Aminoff MJ, Townsend JJ, Feldon S. Continuous cataplexy in a patient with a midbrain tumor: the limp man syndrome. Neurology 1980; 30: 1115-1118.

3. Pritchard PB, Dreifuss FE, Skinner RL, Pickett JB, Biggs PJ. Symptomatic narcolepsy (Abstract). Neurology 1983; 33 (Suppl 2): 239.

4. Rubinstein I, Grey TA, Moldofsky H, Hoffstein V. Neurosarcoidosis associated with hypersomnolence treated with corticosteroids and brain irradiation. Chest 1988; 94: 205-206.

5. Aldrich MS, Naylor MW. Narcolepsy associated with lesions of the diencephalon. Neurology 1989; 39: 1505-1508.

6. Rivera VM, Meyer JS, Hata T, Ishikawa Y, lami A. Narcolepsy following cerebral hypoxic ischemia. Ann Neurol 1986; 19: 505508. 
7. Matsuda Y, Neshige R, Endo C, Abe M, Kuroda Y. A case of upper brainstem infarction developing symptomatic narcolepsy after the administration of anti-convulsant drugs. (Japanese with English abstract) Clinical Neurology 1991; 31: 750-753.

8. Gurewitz R, Blum I, Lavie P, et al. Recurrent hypothermia, hypersomnolence, central sleep apnea, hypodipsia, hypernatremia, hypothyroidism, hyperprolactinemia and growth hormone deficiency in a boy-treatment with clomipramine. Acta Endocrinol (Copenh) 1986 (Suppl); 279: 468-472.

9. Schwartz WJ, Stakes JW, Hobson JA. Transient cataplexy after removal of a craniopharyngioma. Neurology 1984; 34: 13721375.

10. Kowatch RA, Parmelee DX, Morin CM. Narcolepsy in a child following removal of a craniopharyngioma. Sleep Res 1989; 18 : 250.

11. Onofrj M, Curatola L, Ferracci F, Fulgente T. Narcolepsy associated with primary temporal lobe B-cells lymphoma in a HLA DR2 negative subject. J Neurol Neurosurg Psychiatry 1992; 55: 852853.
12. Kish SJ, Mamelak M, Slimovitch C, et al. Brain neurotransmitter changes in human narcolepsy. Neurology 1992; 42: 229-234.

13. Matsumura A, Ahyai A, Hori A, et al. Intracerebral subependymoma clinical and neuropathological analysis with special reference to the possible existence of a less benign variant. Acta Neurochir 1989; 96: 15-25.

14. Scheithauer BW. Symptomatic subependymoma. Report of 21 cases with review of the literature. J Neurosurg 1978; 49: 689-696.

15. Aldrich MS. The neurobiology of narcolepsy-cataplexy. Prog Neurobiol 1993; 41: 533-541.

16. Honda Y, Juji T, Matsuki K, et al. HLA-DR2 and DW2 in narcolepsy and in other disorders of excessive somnolence without cataplexy. Sleep 1986; 9: 133-142.

17. Fernandez JM, Sadaba F, Villaverde FJ, Alvaro LC, Cortina C. Cataplexy associated with midbrain lesion. Neurology 1995; 45: 393.

18. D'Cruz OF, Vaughn BV, Gold SH, Greenwood RS. Symptomatic cataplexy in pontomedullary lesions. Neurology 1994; 44: 2189. 